Working Paper in Economics No. 756

\title{
Nudging as an Environmental Policy Instrument
}

\section{Fredrik Carlsson, Christina Gravert, Olof Johansson- Stenman, and Verena Kurz}

Department of Economics, April 2019 


\title{
Nudging as an Environmental Policy Instrument
}

\author{
Fredrik Carlsson*, Christina Gravert ${ }^{\xi}$, Olof Johansson-Stenman`, and Verena Kurz ${ }^{\S}$
}

\begin{abstract}
We discuss the use of green nudges - nudges intended to reduce negative externalities - as an environmental policy instrument. A review of empirical studies reveals that green nudges can have a sizeable impact on behavior and the environment, but that the effects are context dependent. In the policy discussion, drawing on both the empirical overview and basic welfareeconomic models, it is emphasized that while green nudges seem to have a large potential, they offer no panacea for solving environmental problems. Instead, they should be seen as a policy instrument among others in the regulator's toolbox. In particular, we discuss the potential role of nudging when environmental externalities can be dealt with using optimal Pigovian taxes, and when they cannot. Nudging has a greater potential when such taxes are not available or feasible.
\end{abstract}

Key-words: nudge, environmental policy, behavior

JEL codes: D90, H21, H23

\footnotetext{
* University of Gothenburg, Department of Economics, Box 640, 40530 Gothenburg, Sweden; Telephone: +46 31 7864174; e-mail: fredrik.carlsson@economics.gu.se.

$\xi$ University of Copenhagen, Department of Economics, Øster Farimagsgade 5, 1353 Copenhagen K, Denmark; email: cag@econ.ku.dk

$\zeta$ University of Gothenburg, Department of Economics, Box 640, 40530 Gothenburg, Sweden; Telephone: +46 31 7862538; e-mail: olof.johansson@economics.gu.se.

$\S$ University of Gothenburg, Department of Economics, Box 640, 40530 Gothenburg, Sweden; e-mail: verena.kurz@web.de.
} 


\section{Introduction}

Behavioral interventions, most prominently in the form of nudges, are rapidly entering the public policy toolkit. A nudge is generally interpreted as a change in any aspect of the choice architecture that alters people's behavior in a predictable way without forbidding any options or significantly changing their economic incentives (Thaler and Sunstein, 2009). Originally, the role of nudges was to counteract poor choices made by individuals, in areas such as personal savings and health. While such decisions can create negative externalities such as rising health care costs, the focus has been on improving the individual's own welfare. If it is well designed, a nudge "[...] creates large benefits for those who make errors, while imposing little or no harm on those who are fully rational" (Camerer et al., 2003). Thus, such nudges constitute a behavioral solution to a behavioral problem.

The concept of nudging has also found its way into environmental policy. Nudges are then utilized to influence people's behavior, through changes in the choice architecture, in order to reduce negative externalities. Nudging in this context can then be seen as a behavioral solution to a traditional economic problem.

To distinguish between a nudge that improves the welfare of the individual herself versus a nudge that aims to reduce a negative environmental externality, we will call the latter a green nudge. Thus, a green nudge is a change in any aspect of the choice architecture that is intended to alter people's behavior in a predictable way and result in a reduction of a negative external effect without forbidding any options or significantly changing the economic incentives.

This paper focuses on the role of green nudges as policy instruments. The next section introduces a simple classification of interventions and their underlying motivations, and then we give a review of empirical field studies concerning green nudges. In the subsequent section, we discuss green nudges as an environmental policy instrument. In particular, we discuss when 
green nudges can and should be used as substitutes and complements, respectively, to standard policy instruments such as a Pigovian tax.

\section{A Simple Classification of Interventions and Their Motivations}

Inspired by the classification of policy instruments by Loewenstein and Chater (2017), we classify public policy interventions by type and rationale; see Figure 1. Cell A includes traditional polices used to reduce externalities or asymmetric information, including a standard Pigovian tax or information disclosure. Cell B includes traditional policy instruments that have been adjusted to account for behavioral biases such as inattention. For example, in the case of a tax, an externality with a marginal damage of 1 dollar should be taxed by more than a dollar if people are inattentive to the tax (Farhi and Gabaix, 2018). This category also includes traditional interventions that have a behavioral rationale, such as regulations targeting alcohol consumption or smoking. Inspired by the concept of externalities, the term internalities has been used to describe situations where people make decisions without fully taking the future (or other) consequences for themselves into account (Madrian, 2014). Such internalities can emerge for example if agents have self-control problems or are present-biased. Cell D reflects behavioral interventions that counteract internality and bounded rationality problems with an aim to benefit the individual making the decision. We call these nudges "self-focused" nudges in order to highlight the focus on the individual's utility. In this paper, we focus on Cell C, green nudges. The rationale for such intervention is a traditional economic one, while the type of intervention is behavioral. A green nudge does not aim to correct a "mistake" in decisionmaking but instead uses people's biases and moral utility to nudge them away from creating negative externalities. 


\begin{tabular}{|c|c|c|}
\cline { 2 - 3 } \multicolumn{1}{c|}{} & \multicolumn{2}{c|}{ Type of Intervention } \\
\hline Rationale for Intervention & Traditional & Behavioral \\
\hline Traditional Economic (externalities, & A. Externality-correcting & C. Green Nudge: \\
asymmetric information) & taxes, regulation, & Cognitive and moral \\
Behavioral Economic (internalities, & Information & D. Self-focused \\
bounded rationality) & taxes, regulation, & Nudge: Cognitive and \\
& Information & moral \\
\hline
\end{tabular}

Figure 1. Overview of interventions

Hence, the distinction between self-focused nudges and green nudges is not based on type of nudge, but rather on the rationale for nudging. While self-focused nudges focus on reducing internality problems, green nudges focus on reducing externality problems with behavioral tools. In many cases, externalities and internalities overlap such that a nudge can improve both the decision for the individual and society through a reduction in an externality.

Moreover, we classify nudges - both self-focused and green ones - into two categories depending on how they affect the individual decision-making. We denote these two categories cognitive and moral nudges.

\section{Cognitive Nudges}

We begin by discussing self-focused cognitive nudges aimed to correct for bounded rationality, inattention or self-control problems, and thus to steer behavior mainly by making it easier to "do the right thing." By "the right thing," we mean, in a broad sense, acting in the individual's long-run interest. Self-control problems can result in a divergence between people's intentions and actions, such as dieters who are trying to lose weight but choose high-calorie foods when available (Wisdom, Downs, and Loewenstein, 2010). A present bias builds on the idea that for 
most or even all people, the present carries a disproportionally higher weight than any point in time in the future. This overvaluing of immediate consumption and immediate costs compared with their long-term benefits can lead to suboptimal investments in health or pension savings (O’Donoghue and Rabin, 1999; Thaler and Benartzi, 2004).

In addition, individuals might make sub-optimal decisions for themselves if they base their decisions on mental shortcuts or heuristics. Kahneman (2003) describes the cognitive foundations of heuristics that systematically influence decisions, such as the accessibility of mental contents, the salience of attributes, reference points, and decision frames. Using decision heuristics leads to a context dependency of choices that would not be observed if agents simply solved a utility maximization problem without cognitive or other limitations.

A cognitive self-focused nudge could, for example, be to put healthy foods at the top of a restaurant menu to make them easier to see, or to enroll employees in an employer-matched savings plan by default. These nudges work by making the option that is preferred by the choice architect easier and more salient to the decision maker. Often, as in the case of a default or any given restaurant menu as pointed out by Thaler and Sunstein (2009), it is actually impossible not to nudge. Menus first present either the healthy or the unhealthy options, and the decision makers will be influenced either way.

A cognitive green nudge works in the same way as a cognitive self-focused one, but the motivation for the nudge does not require that the individuals are making a poor choice for themselves because of bounded rationality, inattention, or self-control problems. For example, an individual could make a perfectly rational choice concerning her own welfare by not electing a green electricity tariff. Yet, for a cognitive green nudge to work as intended, individuals must have cognitive or self-control limitations. For example, bounded rationality or self-control could lead an individual defaulted into a green tariff to stick with the new socially desirable default. 
So rather than correcting for a cognitive limitation, a cognitive green nudge makes use of cognitive limitations to encourage socially desirable behavior that may or may not be in the individual's best self-interest.

\section{Moral Nudges}

A moral nudge draws on people's social preferences, their desire for status, to follow norms or to have a positive self-image. The nudge rewards "doing the right thing" by providing the individual with moral (dis)utility. Moral nudges do not rely on bounded rationality or inattention; instead, they work through direct effects on utility. Many of the empirical studies on moral nudges come from the environmental domain, but there are also studies where moral nudges have been used to increase savings (Beshears et al., 2015), enhance tax compliance (Hallsworth et al., 2017), and increase charitable giving (Shang and Croson, 2009). Comparing the decision maker favorably with their neighbor in terms of electricity consumption or highlighting the status that comes with driving an environmentally friendly car are examples of creating moral utility to increase a socially desirable behavior.

\section{Green Nudges - A Review of Empirical Field Studies}

In this section, we review the empirical field studies of green nudges, and discuss their empirical support and why they could affect behavior. We only present field experiments that measure behavioral outcomes and exclude studies with self-reported or hypothetical outcomes and studies with a small sample size. Table 1 presents published studies of green nudges that we review and summarize based on type of nudge and environmental problem. In the text, we also refer to a number of still unpublished studies. 
Table 1. Green nudge field studies published in peer-reviewed international journals

\begin{tabular}{|c|c|c|c|c|}
\hline Study & Description & Target good & Effect size & $\begin{array}{l}\text { Statistically } \\
\text { sign. effect? }\end{array}$ \\
\hline \multicolumn{5}{|c|}{ Default } \\
\hline Arana \& Leon & Opt in vs. opt out & Carbon offsetting of air travel & $+27 \%$ & Yes \\
\hline Brown et al. & Default & Default temperature on thermostat & $-1,8 \%$ & Yes \\
\hline Ebeling \& Lotz & Opt in vs. with opt out & Green energy contract & $+860 \%$ & Yes \\
\hline Egbark \& Ekström & Default & Paper use & $-14 \%$ & Yes \\
\hline Löfgren et al. & Opt in/opt out/active choice & Carbon offsetting of air travel & $-16 \%$ (opt in) $-7.7 \%$ (opt out) & No \\
\hline Toft et al. & Opt in vs. opt out & Purchase of steering unit with heat pump & $-10 \%$ (opt in) $-23 \%$ (opt out) & Yes \\
\hline \multicolumn{5}{|c|}{ Simplification of information and salience } \\
\hline Kurz & Order on menu and presentation & Vegetarian food & $+45 \%$ & Yes \\
\hline Tiefenbeck et al. & Feedback in a salient way & Electricity consumption & $-22 \%$ & Yes \\
\hline \multicolumn{5}{|c|}{ Changes in physical environment } \\
\hline Kallbekken \& Saelen & Change plate size & Food waste & $-21 \%$ & Yes \\
\hline \multicolumn{5}{|c|}{ Reminders } \\
\hline Gillbert \& Zivin & Reminder & Electricity consumption & $-0.89 \%$ & Yes \\
\hline Wallander et al. & Reminder & Sign-up conservation program & $+2.9 \%$ & Yes \\
\hline \multicolumn{5}{|c|}{ Social comparison } \\
\hline Allcott & Comparison & Electricity consumption & $-2.72 \%$ & Yes \\
\hline Asensio \& Delmas & Comparison + framing & Electricity consumption & $\begin{array}{l}+3.8 \% \text { (private framing) } \\
-8.2 \% \text { (social framing) }\end{array}$ & Mixed \\
\hline Ayres et al. & Comparison & Electricity consumption & $-2 \%$ & Yes \\
\hline Bernedo et al. & Comparison, long run & Water use & $-0.89 \%$ & No \\
\hline Brent et al. & Comparison & Water use & $-1 \%--5 \%$ & Mixed \\
\hline Costa \& Kahn & Comparison & Electricity consumption & $-2.1 \%$ & Yes \\
\hline Delmas \& Lessem & Comparison; private and public & Electricity consumption & $-5.6 \%$ (private) $-19.2 \%$ (public) & Yes \\
\hline Ferraro \& Price & Comparison; strong and weak & Water use & $-2.8 \%$ (weak) $-4.6 \%$ (strong) & Yes \\
\hline Ferraro et al. & Comparison, long run & Water use & $-0.16 \%$ (weak) $-0.96 \%$ (strong) & Yes if strong \\
\hline Jaime \& Carlsson & Comparison & Water use & $-5.4 \%$ & Yes \\
\hline Mizobuchi \& Takeuchi & Comparison; financial reward & Electricity consumption & $-6.8 \%$ & Yes \\
\hline Richter et al. & Comparison; varying reference group & Share of sustainability-labeled seafood & $\begin{array}{l}+6 \%-+21 \%(\text { small }) \\
+8 \%-+18 \% \text { (large) }\end{array}$ & Mixed \\
\hline Sparkman \& Walton & Dynamic and static norms & Meatless lunch & $+42 \%($ dynamic $)+36 \%($ static $)$ & Mixed \\
\hline Sudarshan & Comparison & Electricity consumption & $-5.6 \%$ & Yes \\
\hline Pellerano et al. & Comparison, financial reward & Electricity consumption & $-0.6 \%--1.1 \%$ & Yes if no reward \\
\hline
\end{tabular}




\begin{tabular}{|c|c|c|c|c|}
\hline Schultz et al. & Social comparison & Electricity consumption & $\begin{array}{l}+8 \% \text { (descriptive, short run) } \\
-5.7 \% \text { (injunctive, long run) } \\
+2.3 \% \text { (descriptive, long run) } \\
-8.3 \% \text { (injunctive, long run) }\end{array}$ & Mixed \\
\hline \multicolumn{5}{|c|}{ Normative appeal and peer pressure } \\
\hline Ito et al. & Normative appeal & Electricity consumption & $\begin{array}{l}-0.03 \% \text { (short run) } \\
+0.01 \% \text { (long run) }\end{array}$ & Only short run \\
\hline Goldstein et al. & Normative appeal & Towel reuse rate & $+26 \%$ & Yes \\
\hline Kalbekken et al. & Normative appeal & Food waste & $-28 \%$ & Yes \\
\hline Egbark \& Ekström & Normative appeal & Paper use & $-2.6 \%$ & No \\
\hline Schultz et al. & Plea & Recycled waste & $0 \%$ & No \\
\hline Yoeli et al. & Observability & Sign-up energy conservation program & $80 \%-200 \%$ & Yes \\
\hline \multicolumn{5}{|c|}{ Commitment and goal Setting } \\
\hline Baca-Motes et al. & Commitment & Using towel additional days & $+3.5 \%$ (general), $+28 \%$ (specific) & Mixed \\
\hline Bryce et al. & Commitment & Number of weeks household recycled waste & $+13 \%$ & Yes \\
\hline Harding \& Hsiaw & Goal & Electricity consumption & $-0.04 \%$ & Yes \\
\hline Jaeger \& Schultz & Commitment + social norms & Water use & $\begin{array}{c}-3.5 \% \text { (social norm, short run) } \\
-5.6 \% \text { (warning, short run) } \\
-8 \% \text { (social norm, long run) } \\
-3 \% \text { (warning, long run) }\end{array}$ & Mixed \\
\hline Loock et al. & Goal & Electricity consumption & $-2.3 \%$ & Yes \\
\hline Terrier \& Marfaing & Commitment + appeal & Towels replaced in hotel room & $\begin{array}{c}-19.5 \% \text { (commitment) } \\
-20.5 \% \text { (commitment + appeal) }\end{array}$ & Yes \\
\hline
\end{tabular}


The by far most common type of green nudge that has been investigated in a peer-reviewed journal is some sort of moral nudge, and in particular moral nudges where the individual behavior is compared with a reference group. Most of the studies focus on the area of electricity and water consumption, and most reductions recorded range from 1 to 5 percent. Default nudges constitute the second most common type of nudge analyzed in the literature, and most of the published studies find statistically significant effects of them. However, due to publication bias, the effectiveness might be overstated and should be interpreted with caution.

\section{Cognitive Green Nudges}

We classify defaults, simplification of information and salience, and changes to the physical environment as cognitive nudges. We also include reminders here, even though they are a hybrid between cognitive and moral nudges.

\section{Defaults}

The default effect refers to the tendency of people to stick with an alternative already chosen by someone else, even when the cost of making an active choice is very small (Johnson and Goldstein, 2003). The perhaps most well-known example of a prosocial default nudge is the one of organ donors, where the fraction of people who are willing to donate their organs is substantially higher in countries where people are organ donors by default (Johnson and Goldstein, 2003). Sunstein and Reisch (2013) identify three principal factors why defaults can influence behavior. First, people may interpret the default as a suggestion from someone - an expert or a policymaker - who has additional information justifying the recommended option. Thus, setting a default can lower the decision costs for some individuals. Second, people may put off deciding altogether, and then providing a default choice may result in them moving from 
no decision at all to the pre-set decision. Finally, loss aversion or status quo bias can contribute to a default effect, as many individuals will evaluate available options in comparison with the default

A few studies look at default effects and environmentally friendly behavior. Egebark and Ekström (2016) found a default effect on computer printing behavior: by changing the default printer setting from simplex to duplex, the consumption of printer paper dropped by around 15 percent, and there were no indications that the effect was any smaller 28 weeks after the change had been introduced. Pichert and Katsikopoulos (2008) illustrate with two examples that many German electricity consumers stick with an environmentally friendly default option. Ebeling and Lotz (2015) compared customer choice of green energy between an opt-in and an opt-out case. In the opt-in treatment group, 0.6 percent purchased a green contract, while in the opt-out group the figure was 5.6 percent. In Brown et al. (2013), the default temperature on thermostats was changed from the standard $20{ }^{\circ} \mathrm{C}$ to a lower default. While a 1-degree decrease resulted in a lower average temperature initially, the effect disappeared and went into the opposite direction after a few weeks. What this suggests is that a default will only have an impact if it is close to people's actual preferences. Johnson and Goldstein (2003) suggest that strong preferences for a certain option will determine the effectiveness of a default option. That is, individuals with strong preferences for another option than the default will be more likely to override it. However, there is little empirical evidence supporting this claim, partly because underlying attitudes and preferences are hard to measure. Vetter and Kutzner (2016) did not find any interaction effect between environmental attitudes and a green default in a survey-based online experiment. Löfgren et al. (2012) conducted a field experiment with experienced users in the domain of carbon offsetting and found no difference in the choice to offset emissions from flying between a default to compensate, a default not to compensate, and an active choice setting. They concluded that experience attenuates default effects. 


\section{Simplification of Information and Salience}

If decision makers are inattentive to some factors of a decision problem, they will come to a different solution than predicted by conventional economic utility maximization with full information. Chetty, Friedman, and Kroft (2009) found that shoppers pay only limited attention to a sales tax compared to the price before tax. Similarly, Allcott (2011) and Allcott and Taubinsky (2015) found that consumers pay little attention to fuel and electricity costs compared with the sales prices they face when buying cars or lightbulbs. This does not have to be irrational in a broader sense; it would be a rational strategy to limit costs of information acquisition and decision to cope with the multitude of decisions individuals have to make in everyday life (see, e.g., Caplin and Dean, 2015).

The design of different types of consumer product labels is a primary example of simplification of information. In Kallbekken et al. (2013), electrical retail stores provided information on lifetime energy costs of appliances through a label and training of staff. A strong, but primarily initial, effect was found for only one type of appliance, namely dryers, for which the provision of a label and staff training led to a 4.9 percent reducing in energy use for sold units. Other studies have also found mixed results. Stadelmann and Schubert (2018) found effects of both providing a label per se and of a visually augmented label containing monetary and lifetime-oriented information on the energy efficiency of dryers and vacuum cleaners sold, but not freezers. However, the primary purpose of a label is to provide better information in order to improve choices made, which is not a nudge per se. A label could still reduce problems of inattention, but it is difficult to know how large this effect is.

The order in which information is presented can affect the salience of the information. In Kurz (2018), the salience of a vegetarian option was increased by changing the menu order and placing the dish at a place visible to customers. This resulted in an increase in the share of 
vegetarian dishes sold by 6 percentage points. In Gravert and Kurz (2017), a similar effect was found by rearranging a menu in favor of a vegetarian option. Placing the vegetarian dish at the top of the menu reduced the share of meat dishes ordered from 50 percent to around 30 percent. In a study by Tiefenbeck et al. (2016), real-time feedback on energy use was given in the form of an animation of a polar bear standing on melting ice. The visual feedback reduced the average shower time by 22 percent.

\section{Changes in the Physical Environment}

The physical environment itself may be important if people have limited attention, or if the environment provides barriers to preferable behavior. The physical environment can also give clues on appropriate conduct.

Kallbekken and Saelen (2013) evaluated a green nudge provided through the physical environment, with an aim to reduce food waste in buffet restaurants. In one treatment, the nudge consisted of providing plates that were almost 50 percent smaller than the standard ones. The effect on food waste was substantial, with a reduction of around 20 percent.

Designs of the physical environment are often used for waste and recycling: designs of waste bins, and footsteps to the waste bin are some examples of nudge. There are, however, few academic and adequately statistically powered evaluations of such nudges.

\section{Reminders}

Reminders fall somewhere between cognitive and moral nudges. A reminder increases attention to a decision and reduces forgetfulness. However, reminders can also impose moral costs if they draw attention to a decision that the decision maker would rather avoid (Damgaard and Gravert, 2018). For example, being reminded can create guilt and/or cognitive dissonance. 
Wallander, Ferraro, and Higgins (2017) investigated the effect of reminders on participation in voluntary land conservations programs and found that a reminder sent out to participants with expiring contracts increased participation rates. There was no additional effect of letters providing peer comparisons and social norms messaging. Gilbert and Zivin (2014) investigated the effect of receiving the electricity bill, which is a type of reminder, on hourly electricity consumption. They found a .6-1 percent reduction in electricity consumption following receipt of the bill, but that the effect varied considerably across households and seasons.

Gosnell et al. (2017) sent reminders with personalized targets to airline pilots to encourage them to fly more fuel efficiently. In the subsequent eight months, the airline saved more than 6.8 million kilograms of fuel mostly due to a Hawthorne effect of the monitoring. However, the individual target treatments added another 1-10 percent in fuel savings.

\section{Moral Green Nudges}

We now turn to the green nudges that make use of people's social preferences and their desire for status, for a positive self-image and to adhere to social norms. First, we discuss green nudges relating to inter-personal motivations. These are comparisons between the decision maker and their peers, using both descriptive and injunctive norms. Then we present green nudges that make use of individuals' intra-personal motivation. Theses nudges are based on the assumption that people wish to act in a consistent manner, and are related to pleas, commitment and goal setting.

\section{Social Comparisons and Social Preferences}

One important driver of human behavior is the desire for prestige, success relative to others, and esteem. There is extensive empirical evidence that people care about their status and relative consumption (Frank, 1985; Solnick and Hemenway, 1998; Johansson-Stenman, 
Carlsson, and Daruvala, 2002). Sexton and Sexton (2014) use the term "conspicuous conservation" to describe consumption that signals pro-environmental action and generates green status.

There can also be direct reasons for acting in a certain way that do not involve any direct comparison with what others do. For example, there could be altruism, about the environmental impact of one's own consumption on others (Andreoni, 1990; Kotchen and Moore, 2008).

In several studies, social information, i.e., information about other people's behavior, has been provided with the intention to influence people's decisions based on the idea that individuals tend to conform to the behavior of others. Cialdini (2003) suggests that the extent to which social information affects behavior depends not only on the actual information regarding what others do (i.e., descriptive messages) but also on whether it conveys approval of certain behavior (i.e., injunctive messages). Norms can be particularly powerful in unfamiliar situations where decision makers might look to others to receive cues on how to behave.

A series of randomized field experiments aimed at water and energy conservation suggests that the provision of both descriptive and injunctive messages can affect individuals' behavior by reducing water and electricity use (e.g., Allcott, 2011; Ferraro, Miranda, and Price, 2011; Ferraro and Price, 2013; Costa and Kahn, 2013; Ayres, Raseman, and Shih, 2013; Bernedo, Ferraro, and Price, 2014; Allcott and Rogers, 2014; Brent et al., 2015; Jaime and Carlsson, 2018). A statistically significant effect on behavior is often found, although the size of the effect varies considerably. For example, Allcott (2011) found a 2 percent reduction in electricity use and Ferraro and Price (2013) found a 3-5 percent decrease in water use. The majority of the studies in this area were conducted in the U.S. A large study carried out in Germany suggests that the effects on behavior of norm messages are almost non-existent there (Andor et al., 2017). Similar effects as in the US studies were found only for high energy-use households. The main 
explanation by Andor et al. (2017) for the absence of an average effect is that there is simply less room for a reduction if the initial energy use level is already quite low.

There are also interesting developments in the exploration of how social information is communicated. One example is the study by Delmas and Lessem (2014), who studied the effect of both private information to the household and public information to all neighbors on electricity use. They found that only a combination of private and public information had an effect on energy use (a 20 percent reduction). Sparkman and Walton (2017) investigated the role of dynamic norms (information on how other people's behavior changes) and found a stronger effect of dynamic norms than of standard static norm.

\section{Moral Pleas}

Some types of nudges are linked to social preferences but do not directly involve social comparisons (e.g., Schultz, 1999; Goldstein, Cialdini, and Griskevicius, 2008). In Ito, Ida, and Tanaka (2018), moral suasion was used to reduce energy use during peak hours. The following message was received by some households: "Substantial energy conservation will be required for the society during critical peak-demand hours in summer and winter." This was compared with a control group and a group that received economic incentives to reduce energy use. Electricity use was reduced by around 8 percentage points in the moral suasion group and by around 15 percent by the households that received economic incentives. However, the effect of moral suasion diminished quickly when repeated, while the effect of the economic incentives did not. In Egebark and Ekström (2016), a moral message was provided in order to reduce the use of printer paper, but no effects were found. 


\section{Commitment and Goal Setting}

The nudges based on commitment and goal setting relate primarily to problems with selfcontrol, and with green nudges they are often based on the fact that individuals want to see themselves as "good people" (Akerlof and Kranton, 2000; Benabou and Tirole, 2006). Identity can be a driver of behavior if an action is important for one's "sense of self" (Akerlof and Kranton, 2000), and people gain utility by behaving in line with what they perceive as consistent with their self-image. In contrast, actions that conflict with moral values, beliefs, or convictions can cause cognitive dissonance (Festinger, 1957), a feeling of mental discomfort. Concerning environmental actions, people who define themselves as "green" are likely to strive for consistency by avoiding environmentally unfriendly behavior.

Harding and Hsiaw (2014) investigated how voluntary goal setting concerning electricity savings affects actual electricity use and found that those who set a realistic goal save more than those who set a too low or too high goal. Loock, Staake, and Thiesse (2013) looked at how goal setting affects energy savings and found that both individual and default goals lead to significant savings, but that default goals that deviate too much from self-set goals could be detrimental for energy savings. In Kormos, Gifford, and Brown (2015), goal-setting was combined with descriptive social norm information to influence private vehicle use. Goalsetting alone had a small effect on private vehicle use, but when combined with a description of what other had done, the effect became considerably larger.

Offering voluntary ways to commit is a stricter nudge than just setting goals. In Gine et al. (2010), smokers received a savings account offer. If they opted into the program, they had to deposit money into the account. After six months, they got their money back if they passed a urine test; otherwise, the money was given to charity. Eleven percent of the smokers accepted the offer. The rate of cessation was around 3-6 percentage points higher for those enrolled in the program than for a control group. In Baca-Motes et al. (2013), some hotel guests were given 
the opportunity to commit to acting more sustainably and received a pin enabling them to signal commitment. Treated guests were more likely to reuse their towels than those who were not asked to commit. The effect of the commitment was stronger if they received a pin, and it was also stronger if the commitment was more specific (reuse towels) than general (act in an environmentally friendly way).

\section{Green Nudges and Conventional Policy Instruments}

The design of traditional instruments such as taxes and regulatory standards when consumers are inattentive or bounded rational behavioral limitations have been discussed in the literature to some extent (Tsvetanov and Segerson, 2013; Allcott, Mullainathan, and Taubinsky, 2014; Heutel, 2015; Farhi and Gabaix, 2018). For example, if individuals misperceive tax, then the optimal behavioral Pigovian tax should be adjusted in accordance with the extent of the misperception. (Farhi and Gabaix, 2018). Think of a case where individuals misperceive the price of a good by a constant factor. The optimal tax would then be the marginal damage plus this misperception factor. Yet, as far as we know, almost no work (with the exception of Carlsson and Johansson-Stenman, 2018) is based on optimal nudging in the presence of externalities, with or without other behavioral failures.

The role of a green nudge as a policy instrument will critically depend on a number of factors. How does the nudge compare with a traditional policy instrument in feasibility and implementation costs? How does it compare to other policies in its effectiveness in reducing the externality? What other policies can be implemented? What are the implementation costs of the nudge?

Very few direct comparisons of the effectiveness of green nudges with that of traditional policy instruments have been made. Ito et al. (2018) compared effects on energy demand between moral suasion and economic incentives, and found that long-term economic incentives 
worked better than moral suasion to reduce energy consumption. Benartzi et al. (2017) compared a social norm message Allcott (2011) with discounts of the electricity bill in Ito (2015) and found that for the nudge $27.3 \mathrm{kWh}$ was saved per dollar spent on the intervention, while for the discount the figure was only $3.41 \mathrm{kWh}$. Finally, Whittington and Nauges (2018) found that the net-benefits for society are likely to be higher for a price instrument than for a social-information nudge, but that price increases also imply that households would bear most of the costs.

An important factor to consider is the cost of implementing and providing a nudge. Some nudges only require a minimal change in the choice architecture or a change in the framing of communication. The best example of this is perhaps default nudges, where either a default option is implemented or the existing default option is redesigned. Many other nudges require non-negligible fixed costs and/or variables costs. While one might think that such nudges are cheap, they often are not (Allcott and Kessler, 2017). Sending norm messages, or reminders, and giving feedback and measuring goals, etc. result in implementation costs. The extent of these costs depends on the type of nudge and whether it involves smaller adjustments of current systems (e.g., adding a small message to electricity bills) or more fundamental changes (estimating and then designing information about relative electricity consumption). If we compare the costs of a nudge to changing the level of an existing environmental tax, the administrative costs are in most cases larger for a nudge. Yet, if there is no existing tax or if it is difficult to implement a new tax, then a tax will also involve non-negligible costs, and these costs may sometimes be larger than the corresponding administrative costs for nudging.

There are also potential differences between nudges and taxes in terms of enforcement costs. While one might initially think that the enforcement costs associated with nudges should be smaller than for other instruments, this is actually not at all clear. The implementation cost would be small or even non-existent to the extent that they would be implemented voluntarily 
by private firms. Yet, if the government would need to ensure that private firms are actually implementing certain nudges, there is no reason to believe that the enforcement costs would be low.

\section{Optimal Cognitive Nudging}

We will primarily base our discussion here on the models in Carlsson and Johansson-Stenman (2018), who look at pro-social nudging, and to some extent on the more general models in Farhi and Gabaxi (2018). To begin with, consider a simple textbook model with identical individuals and two goods, one clean and one dirty, each of which generates a negative environmental externality. The objective of the government is to maximize the sum of utilities, which is here equivalent to obtaining a Pareto-efficient allocation since individuals are identical.

\section{With an Optimal Pigovian Tax}

Let us start with the conventional assumption that the externality can be perfectly targeted by a Pigovian tax, without any administrative costs. In such a world, it is easy to show that there is no role for green cognitive nudging, since the first-best optimum can be achieved with a Pigovian tax alone. Thus, the government sets a tax equal to the marginal damage, and a firstbest optimum is achieved.

\section{With no Other Regulation}

Consider next the extreme case where no taxes or any other conventional policy instrument can be used. Furthermore, suppose that a nudge can be used without costs and that it perfectly targets those individuals who are causing the externality. As we have discussed, there are many different cognitive nudges affecting individual behavior through different channels. In the literature, this has primarily been modeled in two different ways. The first is to let the nudge 
affect the decision utility, which in turn will affect behavior. Here a difference between (ex ante) decision utility and (ex post) experienced utility is often explicitly modeled in order to allow for an internality (Gabaix and Farhi, 2018). The second is to let the nudge affect the perceived price of a good, which in turn will affect behavior (Gabaix and Farhi, 2018). An internality is then modeled as a misperception of prices. The two approaches are under most circumstances equivalent.

We will here illustrate the role of a nudge in a model setting where it affects perceived prices. Carlsson and Johansson-Stenman (2018) model a conventional cognitive nudge as a nudge that increases the perceived relative price of a dirty good. Under this setting, the optimal level of a nudge implies that the perceived relative price is the same relative price that would be the result of a Pigovian tax.

Let us illustrate with a numerical example. Suppose that without any regulation, the prices of both goods are 10 USD, and that the dirty good generates a constant marginal damage of 3 USD per unit consumed. A first-best Pigovian tax is then 3 USD per unit consumed. An optimal nudge, in the absence of a tax, should then result in a perceived relative price of the dirty good of $13 / 10$. The level of the nudge that would be needed depends on how effective the nudge is in affecting the perceived relative price. Gabaix and Farhi (2018) denote the malleability of the perception as the nudgeability. The larger the nudgeability, the lower the amount of the nudge needed.

\section{With a Non-Optimal Tax}

Suppose that a tax can be used but, for whatever reason, is too low. Let us assume that the tax is 2 USD per unit instead of the optimal of 3 USD. The optimal level of a cognitive nudge will still be one that results in a relative price of $13 / 10$. However, since the tax is now internalizing a part of the externality, less of the nudge is needed to obtain the optimum, compared with a 
situation with no taxes on the dirty good. How much to nudge would again depend on the nudgeability.

\section{Administrative Costs}

How do the optimal conditions change with administrative costs? With such costs there is a tradeoff between the social benefit of the nudge and the cost of providing it. If we assume that the effect of the nudge on the relative price is proportional to the level of the nudge, it can be shown that the optimal level of the nudge depends on the effect of the nudge on the marginal damage and the cost of changing the perceived relative price. (Carlsson and JohanssonStenman, 2018). This means that the optimal level of the nudge is decreasing in the level of the marginal cost of providing the nudge. Moreover, when we introduce administrative costs, a corner solution of zero nudging may be optimal also when the taxes are not optimal.

\section{Adding Internalities}

So far, we have assumed that there are no internalities. What happens if there are also some types of internalities involved? In Carlsson and Johansson-Stenman (2018), this is illustrated as a bias in the perceived price: individuals misperceive the true price of the dirty good. This misperception of the true price could stem for example from inattention. The optimal level of the nudge then also depends on the extent of this bias. The larger the bias, the stronger the nudge needs to be. Similarly, an optimal tax needs to be corrected in the same manner. Consider the same example as before and with no administrative costs. Both goods cost 10 USD and the marginal damage is 3 USD. Let us focus on a situation where the perceived price of the dirty good is lower than the actual price, for simplicity suppose it is 9 USD. An optimal nudge or an optimal tax would then have to change the relative price of the dirty good from 9 USD to 13 USD, if we disregard administrative costs. 


\section{Optimal Moral Nudging}

With a moral nudge, we assume that the nudge directly affects people's utility and that people care about their own perceived morality (in addition to the goods and environmental quality). Following again Carlsson and Johansson-Stenman (2018), we assume that perceived own morality is decreasing in consumption of the dirty good. The strength of the moral norm is influenced by the nudge as follows: the stricter the norm, the larger the importance of morality.

Our line of reasoning is similar to that for cognitive nudges. Consider the case without administrative costs and with no possibility to tax the dirty good. An optimal nudge should lead to the same allocation of the clean and the dirty good as with an optimal Pigovian tax. However, with a moral nudge there could also be a direct utility effect from a strengthened moral norm. This effect could be positive, e.g., that people are proud if they manage to reduce the consumption of the dirty good. Allcott and Kessler (2017) denote such utility effects moral subsidies, and Carlsson and Johansson-Stenman (2018) call such nudges encouraging nudges. The effect could also be negative, e.g., that people feel bad because of their consumption of the dirty good. Carlsson and Johansson-Stenman denote such nudges discouraging nudges. As with cognitive nudges, we will discuss the role of moral nudges with and without optimal Pigovian taxes. Here we directly consider administrative costs.

\section{With an Optimal Pigovian tax}

Even when a Pigovian tax is feasible, it might be optimal to provide an encouraging moral nudge. The welfare effect of this nudge would then purely come from the direct hedonic effect of being moral on utility. The level of the nudge would depend on the marginal benefit in terms of increased moral utility and the marginal cost of providing it (Carlsson and JohanssonStenman, 2018). In contrast, with an optimal Pigovian tax it would never be optimal to implement a discouraging moral nudge. 


\section{With no Other Regulation}

Without any other regulation, there is more room for moral nudges and now discouraging moral nudges may be optimal. With a discouraging moral nudge, there is a trade-off between the reduction of the negative external effect vs. the direct negative effect on moral utility and the marginal cost of providing the nudge. With an encouraging nudge, there is a trade-off between the reduction of the negative external effect and the direct positive effect on utility vs. the marginal cost of providing the nudge.

\section{Optimal Nudges with Heterogeneous Individuals}

So far, we have based our welfare-theoretic reasoning on a simple model with identical individuals. We will here outline some additional roles of nudging that would arise in a world with heterogeneous individuals.

\section{Targeting}

With heterogeneous individuals, there are a number of cases where a nudge might be optimal even with an externality-correcting tax that is optimal on average but that cannot be differentiated perfectly to obtain the first-best allocation. Suppose that some individuals cause much larger externalities than others when consuming the exact same goods and services, but that the tax can only be differentiated at the goods level. For example, a gasoline tax cannot induce a first-best allocation since most externalities depend on where, when and how a car is used. Another example is non-point source pollution, where there is limited observability of individual emissions. Then if a nudge can target large externality creating individuals in a way the tax cannot, it can be welfare improving. 
A nudge may also be preferred to a tax when there is heterogeneity in both misperceptions of prices (Farhi and Gabaix, 2018) and how individuals are affected by a nudge (Carlsson and Johansson-Stenman, 2018). Think of an extreme situation where half the population have no misperception of prices while the other half underestimate the price of the externalitygenerating good. An optimal tax would then be adjusted upwards because of the underestimation of the price on average. Neither of the two groups would face a tax equal to the marginal damage. If those who underestimate the price are also more nudgeable, then a nudge might be preferred over a tax because it would better target individuals with a biased perception. It is plausible that those who are inattentive, inconsistent or irrational are also on average more easily affected by a nudge.

Furthermore, a tax can be expected to a limited impact when it does not target the end users. For example, airline pilots normally do not have a direct incentive to avoid carbon taxes and hotel guests have no direct incentive to reduce food waste.

\section{Redistribution}

Both a nudge and a tax can have direct monetary distributional effects. The direct monetary effects are presumably larger for a tax. If we assume that the group of people who consume the dirty good is poorer, then a nudge to reduce consumption could be preferred over a tax even when the nudge is costly (cf. Farhi and Gabaix, 2018, p. 27). However, the government can of course deal with distributional issues by making changes in other policy instruments, such as income taxes, which must be accounted for in an analysis of distributional effects.

\section{Crowding Out}

A great deal of empirical evidence suggests that individuals have other motives than monetary self-interest, such as a direct concern for the environment or the well-being of others. This does 
not constitute an argument per se against standard policy instruments. However, it raises the question about the interaction between the policy instrument and non-material motives (Carlsson and Johansson-Stenman, 2012). There are arguments for why a policy based on economic incentives could either crowd in or crowd out other motivations, and the extent of these effects is often highly uncertain. If there are intrinsic motivations for acting pro-socially and these can be crowded out by standard environmental policy instruments, then there could be a role for nudging. One such case could be the use of moral subsidies, which we have already discussed. Another case where crowding out could have implication for the choice of policy instrument is if the crowding-out effect of a nudge is smaller than that of other instruments.

There is little empirical evidence of spillover effects and crowding out by nudges in the field. Chetty et al. (2014) compare the effects of a subsidy and a default enrollment in a pension plan and find that the latter is more effective for a majority of inattentive savers, while the subsidy crowds out savings for the minority of savers who are attentive to it. Jaime and Carlsson (2018) find substantial spillover effects between households targeted by a social information campaign on water savings and untargeted households in the same city.

\section{Additional aspects concerning Nudges as Policy Instruments}

When it comes to the practical implementation of nudges as policy instruments, the following aspects must be considered: For traditional environmental regulations, it is clear who decides on the design and extent of the regulation. With green nudges as policy instruments, we partly enter a new world. Nudges could either be mandated or implemented by the government. In both cases though, the government needs to suggest which nudges to use and allow. In the UK, the Behavioral Insights Team is responsible for this as part of the government. Similar units have been created in the U.S. and Australia, and other countries, the World Bank, and the OECD are following suit. 
One advantage of most nudges is that they can be tested for viability in a pilot study before being rolled out to the entire population. For example, the Danish fat tax was abolished after 15 months due to avoidance behavior and the fact that no visible effects on saturated fat consumption were detected. Here a pilot study could have saved a lot of money and time (Bødker et al., 2016). However, in the case of taxes, the behavioral response mechanism is clear. Raised prices are supposed to reduce consumption. For nudges, there could be dozens of heuristics, biases, and behavioral motivations at play that could be addressed with several types of nudges.

Finally, we want to highlight one important aspect in the traditional nudge literature, namely that of libertarian paternalism, i.e., the idea that the government should not interfere with the freedom to choose (Thaler and Suntein, 2009). When nudging is used as a way to correct for assumed internalities, the ethical discussion related to paternalism is clearly important (Sugden, 2018). How much should the government interfere when people seem to be making mistakes? How do we know that they are making mistakes and are not acting according to their true preferences? Maybe people have the right to make their own mistakes regardless of their preferences? However, when it comes to green nudges, the fundamental reason is to correct for an externality and some of the paternalism-based objections are not present. Yet, governments do try to influence people's behavior by making use of their cognitive limitations or self-control problems, and this is of course something that one can have different opinions about and that deserves further discussion and empirical analysis.

\section{Conclusions}

Green nudges are a new addition to the policy maker's toolkit. We have seen an increase in studies on the use of behavioral interventions to correct for externalities. The rationale for using green nudges makes comparison with traditional policy instruments such as Pigovian taxes 
relevant. For example, we show theoretically that in the case where an optimal tax is feasible and available, the role of nudging is often limited due to higher administrative costs. However, distributional concerns, the possibility of targeting and crowding-out might make them worthwhile even if this is the case. In the case of a non-existing or non-optimal tax, a nudge becomes more viable.

As nudges are by definition context dependent, it is challenging to create general recommendation regarding the use of green nudges. Whether a green nudge or any other policy instruments such as taxes are the most appropriate instrument must be determined on a caseby-case basis. The arguments in this paper are intended to provide a basis on which such evaluations can be made.

\section{Acknowledgments}

Financial support from the Swedish EPA and the Center for Collective Action Research (CeCAR) is gratefully acknowledged. We have received valuable comments from Åsa Löfgren, Andreas Nilsson, Katarina Nordblom, Eva Ranehill, and seminar participants at the Swedish EPA, University of Copenhagen, University of Gothenburg, University of Exeter, University of Sterling, University of Toulouse, as well as participants at the World Conference of Environmental and Resource Economists in Gothenburg 2018. 


\section{References}

Akerlof, G., Kranton, R.. 2000. Economics and identity. The Quarterly Journal of Economics. 115:715-753.

Altmann, S., Falk, A., Grunewald, A. 2013. Incentives and information as driving forces of default effects. IZA Discussion Paper 7610.

Allcott, H. 2011. Social norms and energy conservation. Journal of Public Economics. 95:1082-1095.

Allcott, H. 2013. Consumers' perceptions and misperceptions of energy Costs. American Economic Review. 101:98-104.

Allcott, H., Kessler, J. 2015. The welfare effects of nudges: A case study of energy use social comparisons. NBER Working Paper 21671.

Allcott, H., Mullainathan, S., Taubinsky, D. 2014. Energy policy with externalities and internalities. Journal of Public Economics. 112:72-88.

Allcott, H., Rogers, T. 2014. The short-run and long-run effects of behavioral interventions: Experimental evidence from energy conservation. American Economic Review. 104:300337.

Allcott, H., Taubinsky, D. 2015. Evaluating Behaviorally Motivated Policy: Experimental Evidence from the Lightbulb Market. American Economic Review. 105:2501-2538.

Andor, M., Gerster, A., Peters, J., Schmidt, C. 2017. Social norms and energy conservation beyond the US, Ruhr Economics Paper 714.

Andreoni, J. 1990. Impure altruism and donations to public goods: A theory of warm-glow giving. Economic Journal. 100:464-477.

Araña, J., León, C. 2013. Can defaults save the climate? Evidence from a field experiment on carbon offsetting programs. Environmental and Resource Economics. 54:613-626.

Asensio, O., Delmas, M. 2015. Nonprice incentives and energy conservation. Proceedings of the National Academy of Sciences. 112:E510-E515.

Ayres, I., Raseman, S., Shih, A. 2013. Evidence from two large field experiments that peer comparison feedback can reduce residential energy usage. The Journal of Law Economics and Organization. 29:992-1022.

Baca-Motes, K., Brown, A., Gneezy, A., Keenan, E., Nelson, L. 2012. Commitment and behavior change: Evidence from the field. Journal of Consumer Research. 39:1070-1084.

Benabou, R., Tirole, J. 2006. Incentives and prosocial behaviour. American Economic Review 96:1652-78

Benartzi, S. et al. 2017 Should governments invest more in nudging? Psychological Science 28:1041-1055.

Bernedo, M., Ferraro, P., Price. M. 2014. The persistent impacts of norm-based messaging and their implications for water conservation. Journal of Consumer Policy 37:437-452.

Beshears, J., Choi, J., Laibson, D. Madrian, B. Milkman, K. 2015. The effect of providing peer information on retirement savings decisions. Journal of Finance. 70:1161-1201.

Brent, D., Cook, J., Olsen, S. 2015. Social comparisons, household water use, and participation in utility conservation programs: Evidence from three randomized trials. Journal of the Association of Environmental and Resource Economists. 2:597-627.

Brown, Z., Johnstone, N., Hascic, I., Vong, L., Barascu, F. 2013. Testing the effect of defaults on the thermostat settings of OECD employees. Energy Economics 39:128-134.

Bryce, W., Day, R., Olney, T. 1997. Commitment approach to motivating community recycling: New Zealand curbside trial. Journal of Consumer Affairs. 31:27-52.

Bødker, M., Pisinger, C., Toft, U., Jørgensen, T. 2015. The rise and fall of the world's first fat tax. Health Policy. 119:737-742. 
Caplin, A. and Dean, M., 2015. Revealed Preference, Rational Inattention, and Costly Information Acquisition $\uparrow$. American Economic Review, 105:2183-2203.

Carlsson F., Johansson-Stenman, O. 2012. Behavioral economics and environmental policy. Annual Review of Resource Economics. 4:75-99

Carlsson, F., Johansson-Stenman, O. 2018. Optimal prosocial nudging. Paper presented at the World Congress of Environmental and Resource Economists, Gothenburg.

Chetty, R., Looney, A., Kroft, K. 2009. Salience and Taxation: Theory and Evidence. American Economic Review. 99:1145-77.

Chetty, R., Friedman, J., Leth-Petersen, S., Nielsen, T., Olsen, T. 2014. Active vs. passive decisions and crowd-out in retirement savings accounts: Evidence from Denmark. The Quarterly Journal of Economics, 129:1141-1219.

Cialdini. R. 2003. Crafting normative messages to protect the environment. Current Directions in Psychological Science. 12:105-109.

Costa, M., Kahn, M. 2013. Energy conservation "nudges" and environmentalist ideology: Evidence from a randomized residential electricity field experiment. Journal of the European Economic Association. 11:680-702.

Damgaard, M., Gravert, C. 2018. The hidden costs of nudging: Experimental evidence from reminders in fundraising. Journal of Public Economics. 157:15-26.

Delmas, M., Lessem, N. 2014. Saving power to conserve your reputation? The effectiveness of private versus public information. Journal of Environmental Economics and Management. 67:353-370.

Ebeling, F., Lotz, S. 2015. Domestic uptake of green energy promoted by opt-out tariffs. Nature Climate Change. 5:868-871.

Egebark, J., Ekström, M. 2016. Can indifference make the world greener? Journal of Environmental Economics and Management. 76:1-13.

Farhi, E., Gabaix, X. 2018. Optimal taxation with behavioral agents, Working Paper.

Ferraro, P., Miranda, J., Price, M. 2011. The persistence of treatment effects with norm-based policy instruments: Evidence from a randomized environmental policy experiment. American Economic Review. 101:318-322.

Ferraro, P., Price, M. 2013. Using non-pecuniary strategies to influence behavior: Evidence from a large-scale field experiment. The Review of Economics and Statistics. 95:64-73.

Festinger, L., 1957. A theory of cognitive dissonance. Stanford, Calif: Stanford U.P.

Frank, R. 1985. The demand for unobservable and other nonpositional goods. American Economic Review. 75:101-16.

Gillbert, B., Zivin, J. 2014. Dynamic salience with intermittent billing: Evidence from smart electricity meters. Journal of Economic Behavior and Organization. 107:176-190.

Goldstein, N., Cialdini, R., Griskevicius, V. 2008. A room with a viewpoint: Using social norms to motivate environmental conservation in hotels. Journal of Consumer Research. 35:472482.

Gravert, C. Kurz, V. 2017. Nudging a la carte, Working Paper

Hallsworth, M., List, J., Metcalfe, R., Vlaev, I. 2017. The behavioralist as tax collector: Using natural field experiments to enhance tax compliance. Journal of Public Economics. 148:1431.

Harding, M., Hsiaw, A. 2014. Goal setting and energy conservation. Journal of Economic Behavior and Organization. 107:209-227.

Heutel, G. 2015. Optimal policy instruments for externality-producing durable goods under present bias. Journal of Environmental Economics and Management. 72:54-70.

Ito, K. 2015. Asymmetric incentives in subsidies: Evidence from a large-scale electricity rebate program. American Economic Journal: Economic Policy. 7:209-237. 
Ito, K., Ida, T., Tanaka, M. 2018. Moral Suasion and Economic Incentives: Field Experimental Evidence from Energy Demand. American Economic Journal: Economic Policy. 10:240-67.

Jaeger, C., Schultz, P. 2017. Coupling social norms and commitments: testing the underdetected nature of social influence. Journal of Environmental Psychology. 51:199208.

Jaime, M., Carlsson, F. 2018. Direct and spillover effects of a social information campaign on residential water savings. Journal of Environmental Economics and Management. 92:222243.

Johansson-Stenman O., Carlsson F., Daruvala D. 2002. Measuring future grandparents' preferences for equality and relative standing. Economic Journal. 112:362-383

Johnson, E. Goldstein, D. 2003. Do Defaults Save Lives? Science, 302:1338-1339.

Kahneman, D. 2003. Maps of Bounded Rationality: Psychology for Behavioral Economics. The American Economic Review, 93:1449-1475.

Kalbekken and Saelen, H. 2011. 'Nudging' hotel guests to reduce food waste as a win-win environmental measure, Economics Letters 199:325-327

Kormos, C., R. Gifford, Brown, E. 2015. The influence of descriptive social norm information on sustainable transportation behavior: A field experiment. Environment and Behavior. 47:479-501.

Kotchen, M. Moore, M. 2008. Conservation: From voluntary restraint to a voluntary price premium. Environmental and Resource Economics. 40:195-215.

Kurz, V. 2018. Nudging to reduce meat consumption: Immediate and persistent effects of an intervention at a university restaurant. Journal of Environmental Economics and Management. 90:317-341.

Loock, C. M., Staake, T., Thiesse, F. 2013. Motivating Energy-Efficient Behavior with Green IS: An Investigation of Goal Setting and the Role of Defaults. Mis Quarterly. 37.

Lowenstein, G. Chater, N. 2017. Putting nudges in perspective. Behavioral Public Policy. 1:26-53.

Löfgren, Å., Martinsson, P., Hennlock, M., Sterner, T., 2012. Are experienced people affected by a pre-set default option-Results from a field experiment. Journal of Environmental Economics and Management. 63:66-72.

Madrian, B., 2014. Applying Insights from Behavioral Economics to Policy Design. Annual Review of Economics, 6:663-688.

Mizobuchi, K., Takeuchi, K. 2013. The influences of financial and non-financial factors on energy-saving behaviour: A field experiment in Japan. Energy Policy. 63:775-787.

O’Donoghue, T., Rabin, M. 1999. Doing it now or later. American Economic Review. 89:103-124.

Pellerano, J. A., Price, M., Puller, S. L., Sánchez, G. E. 2017. Do extrinsic incentives undermine social norms? Evidence from a field experiment in energy conservation. Environmental and resource Economics. 67:413-428.

Pichert, D., Katsikopoulos, K. 2008. Green defaults: Information presentation and proenvironmental behavior. Journal of Environmental Psychology. 28:63-73.

Richter, I., Thøgersen, J., Klöckner, C. 2018. A social norms intervention going wrong: Boomerang effects from descriptive norms information. Sustainability. 10:2848.

Sexton, S.E. and Sexton, A.L., 2014. Conspicuous conservation: The Prius halo and willingness to pay for environmental bona fides. Journal of Environmental Economics and Management, 67:303-317.

Schultz, P. 1999. Changing behavior with normative feedback interventions: A field experiment on curbside recycling. Basic and Applied Social Psychology. 21:25-36. 
Schultz, P., Nolan, J., Cialdini, R., Goldstein, N., Griskevicius, V. (2007). The constructive, destructive, and reconstructive power of social norms. Psychological Science. 18:429-434.

Shang, J., Croson, R. 2009. A field experiment in charitable contribution: The impact of social information on the voluntary provision of public goods. The Economic Journal. 119:1422-1439.

Solnick, S., Hemenway, D. 2005. Are positional concerns stronger in some domains than in others? American Economic Review, Papers and Proceedings. 45:147-151.

Sparkman, G., Walton, G. 2017. Dynamic norms promote sustainable behavior, even if it is counternormative. Psychological Science. 28:1663-1674.

Stadelmann, M., Schubert, R., 2018. How Do Different Designs of Energy Labels Influence Purchases of Household Appliances? A Field Study in Switzerland. Ecological Economics. 144:112-123.

Sudarshan, A. 2017. Nudges in the marketplace: The response of household electricity consumption to information and monetary incentives. Journal of Economic Behavior and Organization. 134:320-335.

Sunstein, C., Reisch, L. 2013. Automatically Green: Behavioral Economics and Environmental Protection. Harvard Environmental Law Review. 38:127.

Sugden, R. 2018. The Community of Advantage: A Behavioural Economist's Defence of the Market. Oxford: Oxford University Press.

Thaler, R., Benartzi, S., 2004. Save More Tomorrow ${ }^{\mathrm{TM}}$ : Using Behavioral Economics to Increase Employee Saving. Journal of Political Economy. 112:S164-S187.

Thaler, R., Sunstein, C. 2009. Nudge: Improving Decisions about Health, Wealth, and Happiness. New York: Penguin Books.

Terrier, L., Marfaing, B. 2015. Using social norms and commitment to promote proenvironmental behavior among hotel guests. Journal of Environmental Psychology. 44:1015.

Tiefenbeck, V., Goette, L., Degen, K., Tasic, V., Fleisch, E., Lalive, R., Staake, T. 2016. Overcoming salience bias: how real-time feedback fosters resource conservation. Management Science. 64:1458-1476.

Toft, M. B., Schuitema, G., Thøgersen, J. 2014. The importance of framing for consumer acceptance of the Smart Grid: A comparative study of Denmark, Norway and Switzerland. Energy Research \& Social Science. 3:113-123.

Tsvetanov, T., Segerson, C. 2013. Re-evaluating the role of energy efficiency standards: A behavioral economics approach. Journal of Environmental Economics and Management. 66:347-363.

Vetter, M., Kutzner, F., 2016. Nudge me if you can - how defaults and attitude strength interact to change behavior. Comprehensive Results in Social Psychology. 1:1-27.

Wallander, S., Ferraro, P., Higgins, N. 2017. Adressing participant inattention in federal programs: A field experiment with the conservation reserve program, American Journal of Agricultural Economics 99:914-931.

Whittington, D., Nauges, C. 2018 Social norms information treatments in the municipal water supply sector: Some new insights on benefits and costs, Working Paper.

Wisdom, J., Downs, J.S., Loewenstein, G., 2010. Promoting Healthy Choices: Information versus Convenience. American Economic Journal: Applied Economics. 2:164-78.

Yoeli, E., Hoffman, M., Rand, D., Nowak, M. 2013. Powering up with indirect reciprocity in a large-scale field experiment. Proceedings of the National Academy of Sciences. 110:10424-10429. 